\title{
Beans in the management of diabetes
}

\section{By T. D. R. HockaDAY, The Radcliffe Infirmary, Oxford $O X_{2} 6 H E$}

The benefit of the storage carbohydrate of leguminous plants in the dietary management of diabetics of any severity has been appreciated anew in recent years. These storage galactomannans are one form of dietary fibre, best defined by Trowell and Southgate (Southgate, 1973) as: 'Those polysaccharides and lignins of plant origin that are resistant to hydrolysis by the digestive enzymes of man', but differ in forming a viscous solution or gel with water from the 'fibrous' or insoluble fibres such as bran from cereals.

Before describing direct observations on beans of this type (or extracts from them) some recent changes in attitude to the diet of diabetics may be summarized (Hockaday, 198I).

The main emphasis is now given to ( 1 ) the total energy content of the diet, (2) the periodicity (and duration) of meals and (3) that quality of food (called 'texture' or 'digestibility') that determines the time between its oral entry to the alimentary tract and the absorption of the nutrients into the bloodstream. This last quality is far from simple, as it depends upon interactions between a particular food and others with which it may be eaten, quite apart from the varying function of different guts, and the same gut at different times.

Because these three are now the prime considerations, there is much less emphasis on a low-carbohydrate content of the diet, providing quickly absorbed mono- or disaccharides are avoided, and indeed, relatively high carbohydrate diets have the benefits of (a) slightly improving fasting blood glucose levels, providing the diabetes is mild or the glycaemia is accurately controlled by injected insulin or oral sulphonylureas, and (b) the consequent reduced fat content possibly lowering the liability to arteriosclerosis, though again this may depend upon the nature of the fat eaten as well as its quantity. At any rate, there is now much more emphasis upon the physiological property of how a food as eaten affects the blood glucose concentration, rather than on the chemical constitution of the food on the shelf before cooking.

\section{Experience with bean extract}

A pioneer series of studies was performed by Jenkins and his colleagues from I975 onwards on the properties of guar flour (or gum), which had already been used in the food industry as a thickener (for ice creams or gravies). This consists mainly of the storage galactomannan of the cluster bean (Cyamopsis tetragonoloba) of India. He showed this to have a hypocholesterolaemic effect on patients with abnormally high cholesterol levels (Jenkins et al. 1975) and then that it improved glucose tolerance in both normals and diabetics (Jenkins et al. 1976, 1977) whether or not they were treated with insulin and whether or not they were liable to ketosis. It was particularly effective when combined with pectin as additive to a 
breakfast (Jenkins et al. 1976) but he went on to show that guar alone, taken for $5 \mathrm{~d}$ or 6 months, improved diabetic control. The lower blood glucose values after the test glucose load or test breakfast were accompanied by lower concentrations of insulin in the peripheral blood. This benefit does not come from malabsorption but, as Jenkins clearly showed by urinary xylose and breath hydrogen studies, from retarded but complete absorption (apart from a very small increase in the stool fat content).

\section{High bean diets}

Prompted by these results with guar, Simpson et al. ( $198 \mathrm{r}$ ) have used diets high in legumes (of several different types) over a 6 week study period in diabetics, both insulin- and non-insulin treated. They found the high-legume diet beneficial to the blood glucose control on comparison with a classic low-carbohydrate diet and also saw improvement in the fasting plasma lipid levels. Later studies have shown that the high legume component is certainly necessary for the best responses of the blood glucose level after meals, though it may well be partly the high-carbohydrate aspect of the legume diet in addition to the increase in viscous fibre that is responsible for the improvement in basal glucose levels. Anderson \& Ward (1979) have obtained similar successes.

These changes are not massive ones, but then the diabetics were already well controlled, even on the 'control' low-carbohydrate diet. Indeed, relatively tight control is very likely necessary to gain the 'high carbohydrate' benefit, as opposed to the retarded absorption from viscous fibre. However, as it now appears that control of blood glucose really close to normal levels is necessary for substantial retardation of diabetic tissue damage, any extra measure that will tighten glucose control is to be appreciated. Such an aim must always increase the risk of hypoglycaemia, but the slower absorption of food through the delaying action of the legumes on the digestive process should reduce this risk.

\section{REFERENCES}

Anderson, J. W. \& Ward, K. (1979). Am. F. clin. Nutr. 32, 23 12.

Hockaday, T. D. R. (1981). In Nutrition and Diabetes, p. 23-32 [M. Turner and B. Thomas, editors]. London: John Libbey.

Jenkins, D. J. A., Leeds, A. R., Gassull, M. A., Wolever, T. M. S., Goff, D. V., Alberti, K. G. M. M. \& Hockaday, T. D. R. (1976). Lancet ii, 172.

Jenkins, D. J. A., Leeds, A. R., Newton, C. \& Cummings, J. H. (1975). Lancet i, 1116.

Jenkins, D. J. A., Wolever, T. M. S., Hockaday, T. D. R., Leeds, A. R., Howarth, R., Bacon, S., Apling, E. C. \& Dilwari, J. (1977). Lancet ii, 779.

Jenkins, D. J. A., Wolever, T. M. S., Taylor, R. H., Barker, H. M. \& Fielden, H. (1980). Br. Med. F. $28 \mathrm{r}, \mathrm{I} 353$.

Simpson, H. C. R., Simpson, R. W., Lousley, S., Carter, R. D., Geekie, M., Hockaday, T. D. R. \& Mann, J. I. (1981). Lancet i, I.

Southgate, D. A. T. (1973). Proc. Nutr. Soc. 32, 131 . 